KAPITEL 8

\title{
En ny kunskapshistoria
}

Sommaren 1971 skrev den elvaårige pojken Mats Lidström i Göteborg ett brev till Hans Palmstierna. Han hade nyligen läst ett miljövårdsreportage i ungdomstidningen Kamratposten där Palmstierna medverkat. Reportaget hade skakat om honom. "Är det verkligen så illa med vårt lilla Tellus?" undrade han. Lidström skrev att det var hemskt att det fanns människor som förstörde miljön bara för att tjäna pengar. "Man borde ge dem en riktig läxa", ansåg han, för allt vad de gjorde mot "de nyss födda". Det var nu hans generation som skulle tvingas "kämpa mot människans ev. undergång o existens".

För att ta reda på mer om miljöproblemen hade Mats Lidström köpt Plundring, svält, förgiftning. Han tycke den var oerhört intressant och innehållsrik. Men också nedslående. "Hur kan man vara glad i detta samhälle?” frågade han sig. Flera gånger hade han tagit med sig boken till skolan för att läsa ett kapitel högt. Det var inte många av hans klasskamrater som hade velat lyssna. "Och det är ju ett exempel på, varför jorden ser ut som den gör idag", konstaterade han. Själv funderade han på att i framtiden bli "en sån som sysslar med miljön". ${ }^{562}$

Hans Palmstierna svarade Lidström snabbt, vänligt och utförligt. Han instämde i att pengar och vinningslystnad alltför ofta styrde världens gång. "Jag är liksom du övertygad", fortsatte han, "om att du och de andra som fötts under 50- och 60-talet kommer att få betala nog så dyrt för de missgrepp som min generation och de närmaste generationerna före mig har gjort." Fortsatt miljöförstörelse måste förhindras. Människan behövde skyddas från sig själv: "På sikt blir det en fråga om att överleva eller inte, om vi inte bättrar oss." 
Men nog kunde man ändå vara glad. Det fanns många krafter i samhället som arbetade för att ändra på sakernas tillstånd. Och en sak var säker, betonade Palmstierna: "alltfler lyssnar redan och alltfler kommer att lyssna även om dina kamrater just nu inte gör det”. Tids nog skulle de ändra sig. Han berättade vidare för Lidström att nya lagar var på väg att stiftas. Inom kort skulle det bli "åtskilligt svårare att sälja miljöfarliga produkter”. Även på det internationella planet fanns det anledning att vara hoppfull. Om ett år skulle FN anordna en stor miljökonferens i Stockholm. Visst kunde det ibland kännas som att allting gick för långsamt och att framstegen var för små. Men det fanns ingen anledning till missmod, poängterade han. "Det du och jag tillsammans med många andra kan göra är att försöka få de nödvändiga förändringarna att komma snabbare så att det inte blir för sent." ${ }^{563}$

Brevväxlingen mellan Mats Lidström och Hans Palmstierna ger en inblick i hur kunskap om en miljökris cirkulerade i det tidiga 1970-talets svenska samhälle. Den understryker att kunskapen inte endast var en angelägenhet för vetenskapsmän, politiker, journalister och miljöaktivister. Den kunde även sätta igång tankarna hos en elvaårig skolpojke. Hur skulle världen se ut när han blev vuxen? Vilka utmaningar väntade honom och hans klasskamrater? Var miljökrisen verkligen ett hot mot mänsklighetens överlevnad?

Fem år tidigare hade ett mellanstadiebarns oro inför framtiden knappast formulerats på detta sätt. I mitten på 1960-talet var det endast ett fåtal som talade om att människan stod på randen till en global miljökris. Men under några år i slutet på 1960-talet skedde en genomgripande förändring. Ett samhälleligt kunskapsgenombrott. I den här boken har jag kartlagt och analyserat hur förändringen gick till i det svenska samhället. Det har nu blivit dags för mig att ta ett samlat grepp. Vilka är studiens viktigaste resultat? Vad lär undersökningen oss om miljöfrågornas genombrott i Sverige? Vilka nya insikter ger studien den miljöhistoriska forskningen?

Ett slutkapitel är emellertid inte enbart en plats att sammanfatta och renodla forskningsresultat. Det ger också möjlighet att fundera kring de vägval som gjorts och vad de fått för konsekvenser. Därmed aktualiseras större historievetenskapliga frågor av teoretisk och metodisk art. Vad 
jag särskilt vill reflektera kring här är det kunskapshistoriska angreppssättet. Hur bidrar min studie till att definiera och vidareutveckla det kunskapshistoriska forskningsfältet? Vilka mer generella insikter och perspektiv kan kunskapshistoriker ta med sig från den?

Avslutningsvis vill jag också ta tillfället i akt att lyfta blicken bortom undersökningen. Har den historia jag skrivit någon betydelse för oss i dag? Spelar den gröna vändningen åren kring 1970 någon roll för de globala utmaningar som 2020-talets människor står inför? Kan vi lära oss något av historien? Mina svar på dessa frågor kommer med nödvändighet att vara tentativa och resonerande. Jag är historiker - inte samtidsuttolkare eller politisk visionär. Samtidigt har jag funderat länge kring dessa frågor. Jag har några idéer som jag vill prova att sätta på pränt. Min förhoppning är att dessa historievetenskapligt inspirerade tankar ska stimulera till vidare diskussion och vara något att ta spjärn emot. Men jag ska börja med att kortfattat lyfta fram vad jag anser vara studiens viktigaste resultat.

\section{Miljöfrågornas genombrott i Sverige 1967-1972}

Den första poäng som jag vill göra rör kronologin. Med min studie anser jag mig ha belagt att miljöfrågornas stora genombrott för svenskt vidkommande inträffade hösten 1967. Då skedde en kraftig intensifiering av miljödebatten och dess innehåll förändrades i grunden. Självklart är det möjligt att dra de historiska linjerna längre tillbaka. I idé- och vetenskapshistoriskt hänseende är det sena 1940-talet brytpunkten. Men från ett kunskapshistoriskt perspektiv är hösten 1967 viktigare. Det var först då som kunskap om en miljökris på allvar började cirkulera i det svenska samhället i stort. I ett internationellt perspektiv är detta anmärkningsvärt tidigt. I förlängningen fick detta också, genom Stockholmskonferensen 1972, globala konsekvenser.

Min andra punkt handlar om vilka som var de drivande aktörerna i och för detta genombrott. Här vill jag framhålla de svenska naturvetenskapsmän som gick ut i offentligheten och varnade för en hotande global katastrof. Hans Palmstierna, Karl-Erik Fichtelius, Svante Odén och Georg Borgström med flera bildade en kör av varningsröster. Till- 
sammans gjorde de så att den nationella miljödebatten tog fart och ändrade riktning. De svenska forskarna var en del av en större internationell trend mot mer uttalat politiskt engagerade vetenskapsmän. Men vad som är slående vid en jämförelse med länder av samma storlek som Sverige är hur många, och hur relativt synkroniserade, de svenska forskarna var. I de nordiska grannländerna - som på många andra sätt liknade Sverige - skedde inget liknande de här åren. ${ }^{564}$

Min tredje punkt handlar om hur den samhälleliga förståelsen av miljöproblem förändrades under genombrottsfasen. Kännetecknande för denna period var nämligen att miljöförstörelsen började ses som ett överlevnadsproblem. Därmed kom miljöfrågorna att haka i de två globala hotbilder som redan cirkulerade i samhället: kärnvapenhotet och överbefolkningen. Detta kom att prägla retoriken, visualiseringarna och förståelsen av miljökrisen åren kring 1970. Från det sura regnet, kvicksilvergäddorna och den blyhaltiga bensinen gick det linjer till det globala. För personer som Rolf Edberg, Hans Palmstierna, Erik Isakson och Wolter Arnberg hängde allting ihop. Miljöproblemen var en civilisatorisk kris.

Min fjärde poäng pekar dock i en annan riktning. Genom undersökningen har vi nämligen sett att den svenska miljödebatten innehöll fler spår än det globala och apokalyptiska. För aktörer som Barbro Soller, Birgitta Odén, Stig Tejning och Valfrid Paulsson var den nationella nivån överordnad den globala. På detta plan fördes en mer lågmäld och praktiskt inriktad miljödiskussion. Det fanns där en grundmurad tilltro till att det svenska samhället genom politiska beslut, ambitiösa forskningsinsatser och ett utbyggt internationellt samarbete kunde komma till rätta med miljöproblemen. Jag vill också understryka att aktörer kunde röra sig mellan, eller omfatta bägge, spåren i miljödebatten. Det tydligaste exemplet på detta är Hans Palmstierna.

Den femte punkten som jag vill lyfta fram rör miljöfrågornas politisering och vad denna process gjorde med kunskapen. Jag vill mena att genombrottsfasen i Sverige präglades av en relativ samsyn kring miljöproblemens allvar och vad som behövde göras. Särskilt fanns det en utbredd enighet kring behovet av information och upplysning. Det gällde att höja allmänhetens och politikernas kunskapsnivå. Från 1969 
och framåt blev dock konfliktlinjerna tydligare. Politiker, fackförbund, näringsliv och nya sociala rörelser sökte föra miljödebatten i olika riktningar. Många grupper ville göra frågorna till sina. En konsekvens av detta blev att miljöfrågornas politiska färg i Sverige åren kring 1970 var otydlig, eller kanske rättare sagt skiftande. Det innebar att motstridiga kunskapsanspråk framfördes i offentligheten, också av naturvetenskapliga forskare som Gösta Ehrensvärd och Tor Ragnar Gerholm. Vid tiden för Stockholmskonferensen i juni 1972 var det långtifrån självklart vad som cirkulerade som kunskap och vad som betraktades som ideologiska ställningstaganden.

Detta leder vidare till min sjätte poäng som berör frågan om makten över den samhälleliga cirkulationen. För om det nu var så att många röster höjdes och kunskapen blev alltmer omstridd, vad var det som gjorde att vissa aktörer fick genomslag och andra inte? Vilka kunskapsarenor och samhällskrafter var det som hade störst betydelse för cirkulationen? Jag vill här särskilt lyfta fram Dagens Nyheter som en drivande faktor i den svenska miljödebatten. I studien har vi upprepade gånger sett hur tidningen fungerade som en länk mellan forskarvärlden och allmänheten. Därtill vill jag också understryka den svenska socialdemokratins avgörande - men mångskiftande - roll i och för den historiska utvecklingen. Detta inbegriper sådant som tillsättandet av Naturresursutredningen 1964, inrättandet av Naturvårdsverket 1967, Folksams kampanj "Front mot miljöförstöringen" 1968-1969 och ABF:s studiecirklar kring Plundring, svält, förgiftning. Mot bakgrund av detta kan vi också få en förklaring till varför Hans Palmstierna under sent 1960-tal blev så tongivande. Han hade tillgång till politiska, mediala och organisatoriska resurser som ingen annan samtida miljödebattör var i närheten av. Detta är anmärkningsvärt också i ett internationellt perspektiv. Även de allra mest tongivande aktörerna, som Rachel Carson och Barry Commoner, befann sig i jämförelse med Hans Palmstierna mycket långt från faktiska politiska maktpositioner.

Min sjunde och avslutande poäng rör frågan om miljörörelsernas framväxt. Inom historieskrivningen, liksom i det allmänna historiemedvetandet, har gräsrotsengagemanget en framskjuten position. Enligt detta synsätt var det genom de alternativa rörelserna som miljömedvetandet 
växte fram. I ett land som Danmark kan man med visst fog säga att det var så, men inte i Sverige. Min studie visar att miljöfrågornas stora genombrott här skedde flera år innan det fanns några miljörörelser att tala om. Det var etablerade samhällskrafter - forskarvärlden, de politiska partierna, militären, de stora bokförlagen och dagstidningarna - som var först ute. Men från 1969 blev nya sociala rörelser och den nya vänsterns politiska ritualer allt viktigare för cirkulationen av kunskap. I början på 1970-talet väckte Fältbiologerna och Björn Gillbergs miljögrupper stor uppmärksamhet genom spektakulära direktaktioner. Dessa aktörer förmådde, likt Hans Palmstierna 1967, att omforma den svenska miljödebattens dynamik. Konflikterna med det etablerade samhället blev starkare. Alternativrörelsen blev synlig och begreppet "gröna vågen" slog an. Men jag vill mena att miljöengagemanget i Sverige - på 1970talet liksom i dag - involverade betydligt fler människor än de som var organiserade. Långtifrån alla hade radikala vänstersympatier.

\section{En ny kunskapshistoria}

Jag har nått fram till resultaten ovan genom att arbeta med ett kunskapshistoriskt angreppssätt. Min ambition har varit att skriva en större samhällshistoria om miljöfrågornas genombrott i Sverige. Jag har gjort detta genom att studera cirkulation av kunskap, både i offentligheten och i enskilda människors liv. Genom hela studien har jag lagt stor vikt vid de historiska aktörernas handlingar och den kronologiska ordning som olika saker skedde i. Vad jag därigenom velat visa är att miljöfrågornas samhälleliga genombrott var någonting högst konkret och människodrivet. Det var inte en abstrakt kulturell process som skedde av sig självt. Därför såg den också mycket olika ut även inom det kulturellt relativt enhetliga Skandinavien. ${ }^{565}$ För att kunna skriva denna typ av kunskapshistoria har jag valt att fokusera på en förhållandevis kort tidsperiod. Avgränsningen har gjort det möjligt för mig att anlägga ett vidvinkelperspektiv på samhället.

Mitt angreppssätt skiljer sig i grundläggande avseenden från den tidigare forskning som på olika sätt berört miljöfrågornas genombrott i Sverige. Jag vill understryka att denna forskning är rik och håller hög 
kvalitet. Men perspektiven har både varit bredare och snävare än mina. I kronologiskt hänseende har de centrala studierna på fältet sträckt sig över många decennier. Det innebär att genombrottsåren omkring 1970 bara varit en liten del i en större historieskrivning. Med självklarhet har forskare då inte kunnat anlägga ett samhälleligt vidvinkelperspektiv. Det enda undantaget är Lars J. Lundgrens undersökning av hur försurningen hamnade på den politiska dagordningen $1966-1968 .{ }^{566}$ Detta verk illustrerar dock den andra skillnaden, det vill säga att den tidigare historieskrivningen i tematiskt avseende har varit snävare än min. Intresset har riktats mot specifika teman (försurning, tillväxtkritik, kärnkraft), organisationer (Centerns ungdomsförbund, Naturskyddsföreningen, Socialdemokraterna), medieformer (utbildningsprogrammen, tv-journalistik) och aktörer (Georg Borgström). Därutöver finns det studier av diskurser och bildvärldar för vilken kronologi och aktörer inte stått centralt. ${ }^{567} \mathrm{I}$ förhållande till denna forskning är min studie en hybridform av empirisk undersökning och vetenskaplig syntes. Jag ser det som att min undersökning både fördjupar och sammanbinder befintlig kunskap.

Min karaktäristik av det svenska forskningsfältet har bärkraft även på det internationella. Även där tenderar miljöfrågornas genombrott att studeras utifrån längre tidsperspektiv. Fokus ligger i huvudsak på miljörörelsernas framväxt, vetenskapliga varningsröster, idéhistoriska utvecklingslinjer samt den storpolitiska nivån. ${ }^{568}$ Försök att skriva större samhällshistorier är ovanliga, men förekommer. Såsom Michael Bess studie av franska förhållanden och Frank Uekötters av tyska. ${ }^{569}$ Den studie som har mest gemensamt med min egen är Adam Romes undersökning av det amerikanska Earth Day-firandet den 22 april 1970. Uppskattningsvis 20 miljoner människor deltog i firandet och den mediala bevakningen var enorm. Omkring 1500 college och 10000 skolor anordnade föredrag, debatter och demonstrationer. Firandet kan ses som en manifestation över att det hade skett ett samhälleligt kunskapsgenombrott i USA. Earth Day kanaliserade det växande miljöengagemanget på ett sätt som saknade motstycke i resten av världen vid denna tid. ${ }^{570}$ Europeiska naturvårdsåret 1970 hade exempelvis inte i närheten av samma folkliga förankring och genomslag. 
Inom miljöhistorisk forskning har de händelserika åren kring 1970 karaktäriserats som en avgörande vändpunkt. ${ }^{571}$ Men få historiker utan miljöprefixet talar om tidsperioden i termer av en "ecological turn" eller "grön vändning". Det moderna miljömedvetandets framväxt och utveckling är, som Adam Rome och Frank Uekötter påpekat, svagt integrerat i den allmänna historieskrivningen om efterkrigstiden. ${ }^{572} \mathrm{I}$ större samhällshistorier förbigås fenomenet och processerna ofta med tystnad. Jag anser att ett kunskapshistoriskt angreppssätt, med fokus på samhällelig cirkulation, är ett proaktivt sätt att försöka ändra på detta. För när miljöhistoriker, likt Adam Rome, kan visa att de studerar mycket stora samhällsprocesser och inte kulturella randfenomen så får de också goda argument för att fältets insikter och resultat måste integreras i större historievetenskapliga sammanhang. ${ }^{573}$

Men ambitionen att skriva större samhällshistorier för med sig praktiska utmaningar. Inte minst av empirisk art. Det är de facto enklare att studera elitaktörer som verkade i offentligheten än att studera det stora flertalet som inte gjorde det. Det är också enklare att studera miljöengagemang hos organiserade aktivister än att komma åt vad hemmafruar, skolbarn och pensionärer tänkte och gjorde. Själv har jag under min forskning återkommande brottats med dessa frågor. Det har inte varit självklart hur den kunskapshistoriska metodologiska interventionen ska omvandlas till praktisk forskning. Men genom Hans Palmstiernas rika korrespondens har jag hittat personer som Mats Lidström och Sören Gunnarsson. Via Birgitta Odéns efterlämnade papper och de digitalt sökbara tidningsarkiven har jag funnit andra.

Likväl kan det förstås ändå diskuteras om jag verkligen lyckats med föresatsen att studera samhällelig cirkulation av kunskap. Kanske behövs det ett ännu större och mer varierat empiriskt material för att göra detta? Min förhoppning är likväl att jag genom studien lyckats visa på det fruktbara i att aktivt sträva efter att anlägga ett samhälleligt vidvinkelperspektiv. Jag hoppas framtida forskare vill ta vid där jag satt punkt och bygga vidare på mina resultat. Till exempel genom att mer ingående studera Folksams kampanj "Front mot miljöförstöringen" eller de olika bildningsförbundens verksamhet.

Vad som är minst lika angeläget är att genomföra komparativa och 
transnationella forskningsprojekt av samhällelig kunskapscirkulation. Ramachandra Guha och Joachim Radkau har i brett upplagda synteser visat att miljöfrågornas genombrott verkligen var ett globalt fenomen. ${ }^{574}$ Det som hände i Stockholm och New York åren kring 1970 hade motsvarigheter i Tokyo och New Delhi. Men med en global blick är det inte speciellt lätt att få syn på de människor som i olika sammanhang fick saker att hända. Även mycket inflytelserika aktörer, som Hans Palmstierna i den svenska kontexten, tenderar att bli osynliga. Elvaårige Mats Lidström får knappast plats. Men om miljöhistoriker menar allvar med att vilja integrera fältet $\mathrm{i}$ en bredare historieskrivning så behöver de - anser jag - använda sig av skalor som gör att fler av de många människorna som fick upp ögonen för miljöfrågorna blir synliga. Dessutom behöver konkreta jämförelser göras för att se vad som skiljde olika samhällen åt.

Vad jag också hoppas på är att min studie ska kunna inspirera till kunskapshistoriska studier av andra samhällsfenomen och tidsperioder. Jag är själv övertygad om att aktörsorienterade studier av samhällelig cirkulation av kunskap är ett fruktbart sätt att bedriva historisk forskning. Det finns, som jag ser det, ett växande behov inom historievetenskapen att gå bortom de enskilda fallstudierna och försöka ta större grepp på centrala samhällsfenomen och förändringsprocesser. Jag när inga illusioner om att det går - eller ens är önskvärt - att skriva någon sorts samhällelig totalhistoria. Men inom en vital historievetenskap bör det göras försök att skriva större samhällshistorier. Jag hoppas att kunskapshistoria ska vara en impuls för detta.

\section{En historikers funderingar kring samtiden och framtiden}

Ett drygt halvsekel har gått sedan miljöfrågorna fick sitt stora genombrott i Sverige. Det är en ganska kort tid för en historiker. Det är en försvinnande kort tid för en klimatforskare eller en paleontolog. Men femtio år är en lång tid i en människas liv. Mats Lidströms ungdom och större delen av hans arbetsliv har passerat. De fältbiologer som demonstrerade på Sergels torg i Stockholm 1969 har gått i pension. Hans Palmstierna 
gick bort i en drunkningsolycka 1975. Birgitta Odén dog efter ett långt och aktivt forskarliv 2016. Barbro Soller somnade in i januari 2020.

Ändå är miljöfrågornas genombrott alltjämt en historisk process som många människor har minnen av och kring. I några decennier till kommer händelserna fortsätta att vara samtidshistoria. Men för de allra flesta nu levande, inklusive mig själv, är den gröna vändningen enbart historia. Det är något som hände innan jag föddes. Min kunskap om detta kan aldrig vara annat än indirekt. Jag vill ändå mena att det är en form av levande historia. Det som hände då påverkar oss nu. Den kunskap som cirkulerade i det svenska samhället då påminner starkt om den som cirkulerar här i dag (se tablå 1). Miljömedvetandets framväxt och utveckling är, anser jag, en helt central del av efterkrigstidens historia.

Men under det halvsekel som gått sedan miljöfrågorna fick sitt stora genombrott har såväl problembilden som kunskaperna kring den ändrat form. I dag talar vi om klimatkris snarare än om miljökris. De stigande temperaturerna är den av det moderna industrisamhällets oönskade sidoeffekter som de senaste 15 åren har oroat flest och mest. Det verkligt stora problemet är kanske inte att naturresurserna sinar utan att de inte gör det. Mänskligheten hade måhända varit betjänt av mindre kol- och oljereserver.

2020-talet inleddes med bränder i Australien och smältande isar på Arktis. Därefter har coronapandemin överskuggat det mesta. Många av dagens barn och ungdomar ställer sig därför samma fråga som Mats Lidström gjorde sommaren 1971: "Hur står det egentligen till med vårt lilla Tellus?" Den stora skillnaden är att det i dag sker en global mobilisering på gräsrotsnivå. Fältbiologernas demonstration på Sergels torg 1969 framstår med dagens mått som småskalig. Även Earth Day 1970 bleknar faktiskt i jämförelse med vår tids skolstrejker och klimatmarscher. Någon Greta Thunberg fanns inte under sent 1960-tal eller tidigt 1970-tal. 


\section{Då som nu}

- anlades ett globalt perspektiv på ett sammanflätat problemkomplex

- knöts förhoppningar till en cirkulär ekonomi

- framhöll forskare behovet av autonomi och långsiktighet

- uttrycktes ibland en känsla av maktlöshet inför problemen

- talades det om problemen som "antropogena" och människan som en geologisk kraft (detta redan på 1950-talet, det vill säga ett halvt sekel innan begreppet "antropocen" myntades)

- varnades det för att en blind tillväxttro undergräver vår existensbas

- betonades det hur bråttom det var att styra utvecklingen i nya riktningar

- framförde vissa att det inte räcker med tekniska lösningar, utan att det också krävs samhälleliga lösningar

- $\quad$ antydde vissa röster att demokratin kunde behöva offras om problemen skulle kunna åtgärdas

- menade kampanjmakare att man behövde gå via ungdomen för att nå resten av befolkningen

- talades det om att vi har all kunskap vi behöver, det enda som krävdes var viljan att agera

- höjdes röster för att Sverige skulle ta på sig rollen som globalt föregångsland

- talades det om huruvida vi skulle kunna se våra barn och barnbarn i ögonen

\section{Då till skillnad från nu}

- var miljöfrågorna, åtminstone under genombrottsfasen 1967-1968, av en icke-ideologisk karaktär 
- var miljökrisen ett nytt globalt överlevnadsproblem. Det fanns inte en femtioårig historia av vetenskapliga varningar, politiska initiativ och informationskampanjer

- fanns det ingen organiserad miljörörelse och inga gröna politiska partier

- fanns en stark tilltro till politikers makt och kollektiva lösningar

Tablå 1. Likheter och skillnader mellan den ekologiska vändningen och vår tids klimatdebatt

Skillnaderna till trots kan jag som historiker ändå förvånas över hur frånvarande de medellånga samtidshistoriska perspektiven är i dagens miljö- och klimatdebatt. För mig är de så uppenbart relevanta. Vi som lever i dag är inte de första som sökt förändra samhället i en mer hållbar riktning. Den svenska regeringens visioner om ett fossilfritt Sverige 2045 är inte radikalt annorlunda än 1970-talets visioner om det cirkulära lågenergisamhället. Vad skulle hända om lika stor kraft lades på att blicka bakåt och söka lära av det förflutna som på att simulera och prognosticera framtiden? Missförstå mig rätt. Jag tror inte historien har alla svar på samtidens och framtidens utmaningar. Men jag tror inte heller att den är betydelselös.

Dessutom tror jag att våra skiftande historiska erfarenheter är viktigare än vad den politiska debatten ger sken av. Vetenskapliga varningsröster har kunnat höras under hela efterkrigstiden. Framtidskunskap har cirkulerat i massmedier, parlamentariska församlingar och klassrum. Många människor världen över har oroat sig för kärnvapenkrig, överbefolkning, sinande naturresurser, miljöförstörelse, kärnkraft, ozonhål och klimatförändringar. Men samma människor har också erfarenheter av att framtiden kom och att den stora civilisatoriska kollapsen - än så länge - inte har gjort det. Hur påverkar dessa historiska erfarenheter oss? Håller de oss vakna eller trubbas vi av? Vad tror vi 
egentligen innerst inne om framtiden? Hur skiljer detta sig mellan olika generationer och samhällsgrupper?

Vad gäller det politiska samtalet finns det ytterligare dimensioner. Den period som följer på min undersökning kom för svensk del att präglas av kärnkraftens vara eller inte vara. Detta skakade om det politiska landskapet ordentligt. År 1980 hölls det en folkomröstning och genom den slogs det fast att kärnkraften successivt skulle avvecklas. När jag var barn, på 1990-talet, fick jag lära mig att kärnkraftverken skulle stängas ned till 2010. Så blev inte fallet. Erfarenheterna av detta tror jag också är viktiga. De visar på svårigheterna att ta beslut om vad som ska hända om trettio år. På så lång tid kan och kommer nämligen ett samhälle och dess omvärld att förändras i grunden. Det kan vara värt att påminna oss om när vi blickar mot 2045.

Men historien ger oss också exempel på att stora och långsiktiga förändringar faktiskt går att genomdriva. Miljöfarliga ämnen som DDT och freoner har förbjudits och fasats ut. Kvicksilverhalterna i svensk insjöfisk har under lång tid varit på väg nedåt. Beslut som togs åren kring 1970 har först i våra dagar fått full effekt. Dessa exempel ger en fingervisning om en möjlig historisk lärdom. När problemen är konkreta och avgränsade så finns det goda möjligheter att göra något åt dem. Detta även om genomförandet tar många decennier.

Men de verkligt stora och svåra frågorna är av en annan karaktär. Fossila bränslen genomsyrar våra liv och samhällen. Det gjorde inte DDT, freoner och kvicksilver. Alla det moderna industrisamhällets oönskade sidoeffekter kan kanske inte hanteras med lagstiftning och ny teknik. När det kommer till mer komplicerade frågor är kunskap inte heller alltid så enkel att samlas kring. Den relativa konsensus som kan finnas under ett samhälleligt kunskapsgenombrott följs inte nödvändigtvis av kraftfull politisk handling. Det kan uppstå konflikter mellan olika legitima intressen och målbilder.

Här framträder också en av de största skillnaderna mellan den gröna vändningen och vår egen samtid. När kunskap om en global miljökris fick sitt stora samhälleliga genombrott i Sverige uppfattades miljöfrågorna inte som ideologiska. Företrädare för olika politiska partier och samhällsintressen betraktade dem som vetenskapliga och tekniska 
frågor vilka man på rationell väg kunde göra något åt. Ett historiskt fönster öppnades där en aktör som Hans Palmstierna för en tid kunde fungera samlande. Men i början på 1970-talet hade dynamiken förändrats. Miljöfrågornas ideologiska färg var fortfarande inte entydig, men det rådde ingen tvekan om att de hade stor ideologisk sprängkraft och kunde orsaka djupa och öppna konflikter. Såväl det socialdemokratiska etablissemanget, forskarsamhället, näringslivet, de borgerliga partierna och den nya miljörörelsen var indragna i en stundtals ganska rörig kamp kring vad miljöbegreppet egentligen skulle innefatta och vad man skulle göra åt problemen. En av få saker som det dock verkligen har gått att enas kring är behovet av mer forskning och säkrare kunskap.

Själv funderar jag dock ibland på om miljö- och klimatdebatten i alltför hög grad är och har varit koncentrerad kring just frågor om kunskap. Det förefaller mig som att stora delar av det politiska samtalet är uppbyggt kring en naiv tro på att den som vet det rätta gör det rätta. Vad säger att det är så? Erfarenheten? Vetenskapen? Och hur vet vi när något är "det rätta"? Möjligen är kunskapens centrala plats ett arv från tiden då miljöfrågorna fick sitt stora genombrott världen över. Det sena 1960-talet var på många sätt en kulmen för efterkrigstidens tilltro till vetenskap och rationell samhällsplanering. ${ }^{575}$ Därefter har förtroendet på många håll ersatts av skepsis.

Men vad om inte kunskap kan leda till en hållbar framtid? Ska vi i en tid av polarisering och misstro vända vetenskapen och dess företrädare ryggen? Nej, det menar jag inte. Vad jag dock anser är att grundläggande frågor om hur vi ska leva våra liv - som individer, grupper, samhällen och mänsklighet - inte kan reduceras till frågor om vetenskap. Diskussionerna måste även handla om värderingar, principer och historiska erfarenheter. Därför är också samtidshistorisk forskning viktig för det politiska samtalet. Det ger nämligen, likt all historisk forskning, möjlighet att vidga det egna erfarenhetsrummet och få en inblick i vad som format andras. 